Research Article

\title{
Detection of vancomycin susceptibility among clinical isolates of MRSA by using minimum inhibitory concentration method
}

\section{P. Sreenivasulu Reddy*, Maria Sindhura John, P. Vasundhara Devi, B. Siva Prasad Reddy}

Department of Microbiology, Narayana Medical College, Nellore, Andhra Pradesh, India

Received: 31 March 2015

Accepted: 07 May 2015

*Correspondence:

Dr. P. Sreenivasulu Reddy,

E-mail: sr.palukuru@gmail.com

Copyright: (C) the author(s), publisher and licensee Medip Academy. This is an open-access article distributed under the terms of the Creative Commons Attribution Non-Commercial License, which permits unrestricted non-commercial use, distribution, and reproduction in any medium, provided the original work is properly cited.

\begin{abstract}
Background: Staphylococcus aureus is considered as a major pathogen causing a diversity of infections including bacteremia, pneumonia, skin and soft tissue including osteoarticular infections. Since 1961, Methicillin Resistant Staphylococci aureus (MRSA) emerged has one of the major and common cause of hospital acquired infection. However, due to wide spread usage of vancomycin for MRSA infections resulted in reduced susceptibility of S. aureus to vancomycin has been identified as a serious public health concern. The aim of the study is to identify the Methicillin Resistant Staphylococcus aureus (MRSA) from various clinical samples and to detect vancomycin susceptibility by Minimum Inhibitory Concentration (MIC) method.

Methods: This study was conducted over period of one year December 2013 to November 2014. Clinical samples like pus, blood, sputum, urine and cerebrospinal fluid were collected from various clinical departments in Narayana General Hospital for selective isolation of Staphylococcus aureus. A total of 100 Staphylococcal aureus isolates were isolatedby using standard laboratory procedures. MRSA were detected using Oxacillin Disc on Muller Hinton Agar with $4 \% \mathrm{NaCl}$. Sensitivity pattern for vancomycin $(30 \mu \mathrm{g})$ disc and for other recommended antibiotics was determined by Kirby-Bauer's disk diffusion method. Minimum Inhibitory Concentration (MIC) was done for vancomycin sensitive isolates by standard agar dilution method.

Results: Out of $100 \mathrm{~S}$. aureus isolates, all were susceptible to vancomycin $(30 \mu \mathrm{g})$ by disk diffusion method. But, 82 isolates of MRSA were susceptible to vancomycin at the concentration of $0.5-2 \mu \mathrm{g} / \mathrm{ml}$ of agar. 17 isolates showed intermediate sensitivity to vancomycin, in which 13 isolates with MIC $4 \mu \mathrm{g} / \mathrm{ml}$ and 4 isolates with MIC $8 \mu \mathrm{g} / \mathrm{ml} \mathrm{and}$ one is olate was resistant to vancomycin even with MIC of $16 \mu \mathrm{g} / \mathrm{ml}$.

Conclusions: The present study reveals the emergence of Vancomycin Intermediate Sensitive Staphylococcus aureus (VISA) and Vancomycin Resistant Staphylococcus aureus (VRSA). Disc diffusion method should not be employed for detection of vancomycin sensitivity for MRSA stains. The major cause may be attributed to unawareness and irrational usage of broad spectrum antibiotics.
\end{abstract}

Keywords: MRSA, VSSA, VISA, VRSA, MIC

\section{INTRODUCTION}

Staphylococcus aureus is a major pathogen causing a diversity of infections including bacteremia, pneumonia, skin and soft tissue and osteoarticular infections. ${ }^{1}$ In the past few decades, the prevalence of Methicillin Resistant
Staphylococcus aureus (MRSA) among both nosocomial and community acquired infections has increased throughout the world. ${ }^{2}$ Staphylococci are among the hardest nonspore forming bacteria and they can survive many nonphysiologic environmental conditions. They 
can be cultured from dried clinical material after several months and are relatively heat resistant. ${ }^{3}$

Staphylococci are one of the major groups of bacteria inhabiting the skin, skin and mucous membranes. The skin and mucous offer a very efficient mechanical barrier against local tissue invasion. Infections caused by $\mathrm{S}$. aureus include bacteraemia, endocarditis, respiratory infections, osteomyelitis, pyomyosiits, toxic shock syndrome, central nervous system infections, food poisoning, urinary tract infections, nosocomial infections and infection of eye. Due to the development of multidrug resistance among $\mathrm{S}$. aureus isolates treatment of these infections has become problematic. ${ }^{4}$

For so many years Methicillin and other semisynthetic penicillin were successful in treating penicillin resistant S. aureus infections. ${ }^{5}$ MRSA has emerged as one of the commonest cause of hospital acquired infections and continues to remain an important factor contributing in failure of management. ${ }^{6}$

Predisposing factors for MRSA infections are prolonged hospital stay, close proximity to an infected or colonized patient, underlying diseases like surgical wounds, renal diseases, diabetes mellitus and older age. Presence of indwelling devices such as urinary catheters, indiscriminate usage of antibiotics. ${ }^{7}$

Control of spread of MRSA among the colonized patients and health care personnel is must in the hospital to reduce the increased vancomycin resistance. Screening of hospital staff and eradicating nasal carriage from health care workers is mandatory. ${ }^{8}$ Till recently, vancomycin was the drug of choice for infections produced by MRSA strains. In May 1996, the world's first documented clinical infection due to Staphylococcus aureus with intermediate resistance to vancomycin was detected in a patient in Japan.

Vancomycin is a glycopeptide antibiotic introduced for clinical use in 1958, effective on Gram positive bacteria. The truth is that the bacteria are once again one step ahead. Recently it is getting resistance to vancomycin. It's usage is increased in the last 20 years due to increased prevalence of methicillin resistance among the staphylococcal species. ${ }^{9}$ Risk factors for VISA and VRSA include, diabetes, kidney disease, previous infections with MRSA, in situ intravenous catheters, inappropriate treatment with vancomycin or other antibiotics. ${ }^{10}$

The emerging threat of wide spread vancomycin resistance possesses a serious health concern. Screening for MRSA and other staphylococci with reduced susceptibility to vancomycin is a key component of successful infection control strategies. Thus the present study was taken up to study the susceptibility pattern of vancomycin to MRSA among the clinical isolates.

\section{METHODS}

The study was conducted between December 2013 to November 2014 in the department of Microbiology, Narayana Medical College, Nellore.

Clinical samples like pus, blood, urine, sputum, CSF were collected according to the standard guidelines from various departments of Narayana General Hospital.

\section{Isolation of Staphylococci from clinical samples}

Samples were inoculated on to a nutrient agar, blood agar, MacConkey's agar and incubated at $37^{\circ} \mathrm{C}$ for 24 hrs. The plates were examined for growth on next day and the colonies resembling $\mathrm{S}$. aureus were selected for further characterization and confirmation. The colonies were subjected to gramstaining (Gram positive cocci arranged in clusters), catalase test (production of copious bubbles), coagulase test (clot formation), mannitol fermentation test (broth turns to pink color and no gas production).

\section{Detection of methicillin resistance by disc diffusion method}

The suspension for inoculation was prepared from isolated colonies of the growth from nutrient agar plate. The growth was suspended in $0.5 \mathrm{ml}$ of sterile saline and turbidity was adjusted to 0.5 MacFarland turbidity. A sterile swab was dipped into the suspension and excess inoculum was removed by pressing it against the sides of the test tube. This swab was streaked on the Muller Hinton agar with $4 \% \mathrm{NaCl}$ and the plate was allowed to dry for few minutes. Oxacillin discs were applied within $15 \mathrm{~min}$ after inoculation. The plates were incubated for 48 hours at $35^{\circ} \mathrm{C}$. Zone of inhibition around the disc was measured with the help of a scale and compared with CLSI zone size interpretative chart.

Interpretation: The strain was considered Sensitive, if zone size was $\geq 13 \mathrm{~mm}$, intermediate sensitive if the zone size was $11-12 \mathrm{~mm}$ and resistant if the zone size was $<10$ $\mathrm{mm}$.

\section{Detection of vancomycin resistance by disc diffusion method}

The procedure was same for making the lawn culture and vancomycin disc $(30 \mu \mathrm{g})$ was applied within 15 minutes after inoculation. The plates were incubated for 24 hours at $35^{\circ} \mathrm{C}$. The zone of inhibition was measured with the help of scale and compared with CLSI zone size interpretative chart.

Interpretation: The strain was considered sensitive, if zone size was $\geq 15 \mathrm{~mm}$, and resistant if the zone size was $<15 \mathrm{~mm}$. 


\section{Detection of MIC of vancomycin by agar dilution method}

Serial dilution of the antibiotics are made in Muller Hinton agar and poured into petri dishes. Dilutions are made in distilled water and added to the agar which has been melted and before it gets set in. One control plate was inoculated without antibiotics. Organisms to be tested is inoculated and incubated over night at $37^{\circ} \mathrm{C}$. Plates were examined for the bacterial growth. The concentration at which bacterial growth is completely inhibited was considered as the MIC of the antibiotic to that strain. The organisms were reported as sensitive, intermediate sensitive or resistant by comparing the test MIC values with CLSI guidelines for interpretation.

Interpretation: S. aureus which had MIC of $-2 \mu \mathrm{g} / \mathrm{ml}$ were considered susceptible, $4-8 \mu \mathrm{g} / \mathrm{ml}$ as intermediate, $>16 \mu \mathrm{g} / \mathrm{ml}$ as resistant.

\section{RESULTS}

The present study was conducted in the Department of Microbiology in Narayana Medical College, Nellore. Total 100 MRSA strains were identified from various clinical samples collected from different clinical departments of Narayana General Hospital from December 2013 to November 2014.

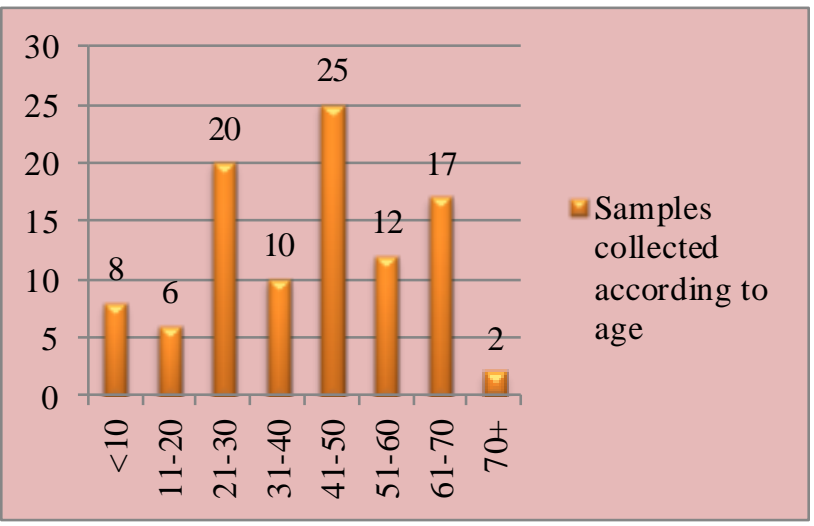

Figure 1: Age wise distribution of samples collected.

Out of 100 samples majority of patients were of the age 41-50 years (25) and minimum no. of samples were from age group $70+(2)$.

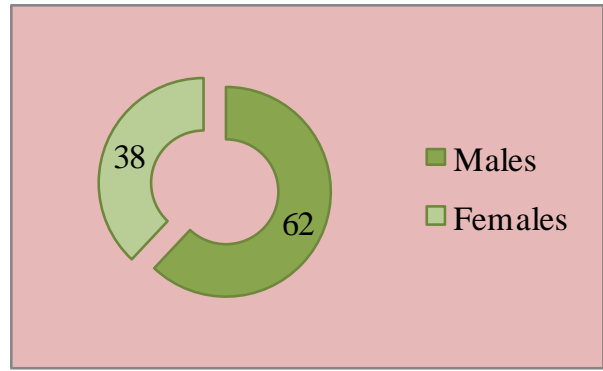

Figure 2: Sex wise distribution.
Out of 100 subjects $62(62 \%)$ patients were male and 38 $(38 \%)$ were female patients.

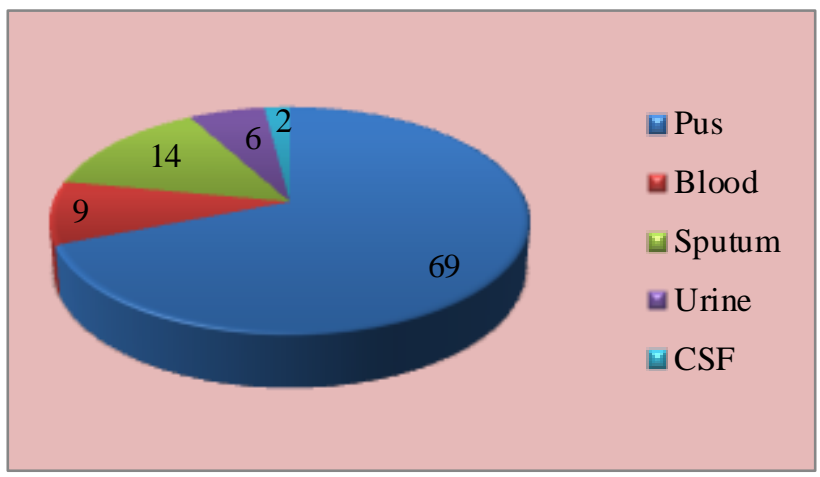

Figure 3: Distribution of total clinical samples.

Among 100 MRSA strains studied 69 were from pus, 9 from blood, 14 from sputum, 6 were from urine and 2 strains from CSF samples.

Table 1: Showing MIC of vancomycin and their corresponding zone of inhibition by agar dilution method.

\begin{tabular}{|c|c|c|c|c|c|c|}
\hline \multirow{2}{*}{$\begin{array}{l}\text { Zone } \\
\text { (mm) }\end{array}$} & \multicolumn{6}{|c|}{ Zone of MIC $(\mu \mathrm{g} / \mathrm{ml})$} \\
\hline & 0.5 & 1 & 2 & 4 & 8 & $>16$ \\
\hline $15-16$ & 0 & 5 & 8 & 5 & 1 & 1 \\
\hline $17-18$ & 3 & 12 & 12 & 6 & 2 & 0 \\
\hline $19-20$ & 12 & 8 & 22 & 2 & 1 & 0 \\
\hline Total & 15 & 25 & 42 & 13 & 4 & 1 \\
\hline
\end{tabular}

In the present study, the MIC of the vancomycin was determined using agar dilution method. Out of which 15 is olates showed MIC of $0.5 \mu \mathrm{g} / \mathrm{ml}, 25$ isolates of MIC 1 $\mu \mathrm{g} / \mathrm{ml}, 42$ isolates of MIC $2 \mu \mathrm{g} / \mathrm{ml}, 13$ is olates of MIC 4 $\mu \mathrm{g} / \mathrm{ml}, 4$ isolates of MIC $8 \mu \mathrm{g} / \mathrm{ml}$ and 1 is olate of MIC 16 $\mu \mathrm{g} / \mathrm{ml}$.

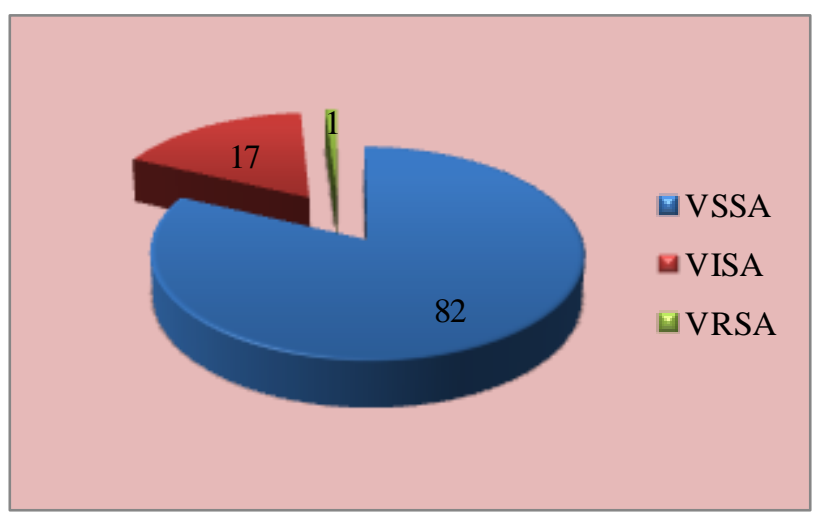

Figure 4: Vancomycin susceptibility pattern by agar dilution method.

Out of 100 MRSA strains, 82 were VSSA with MIC 0.5$2 \mu \mathrm{g} / \mathrm{ml}, 17$ isolates were VISA with MIC $4-8 \mu \mathrm{g} / \mathrm{ml}$ and one strain was VRSA with MIC $>16 \mu \mathrm{g} / \mathrm{ml}$. 


\section{DISCUSSION}

The present study of vancomycin susceptibility among methicillin resistant Staphylococcus aureus isolates from various clinical samples was carried out in Narayana Medical College, Nellore.

Out of 100 patients with MRSA infections, 25 were between the age group 41-50 years (Figure 1). This may be because of waning immunity as age advances and under lying hormonal abnormalities. Majority of the isolates were from males comprising 62 compared 38 among females (Figure 2). Increased rate of infection among males may be attributed to their out-door occupation which is more prone to injuries. Personal habits like smoking and alcoholism. Similar observations were made by Siddique et al. who reported a male to female ratio 2.6:1(10). 100 MRSA strains were isolated from different patients, out of which 69 were pus, 6 were blood, 14 sputum samples, 6 were urine and 2 were CSF samples (Figure 3).

In the present study, vancomycin susceptibility was determined by Kirby-Bauer disc diffusion method and MIC was calculated by agar dilution method. All MRSA strains were susceptible to vancomycin by disk diffusion method (Table 1). But, MIC value of 100 is olates varied from $0.5-16 \mu \mathrm{g} / \mathrm{ml}$ (VRSA). 82 strains had MIC between $0.5-2 \mu \mathrm{g} / \mathrm{ml}, 17$ strains had MIC between $4-8 \mu \mathrm{g} / \mathrm{ml}$ (VISA) and 1 strain had MIC of $16 \mu \mathrm{g} / \mathrm{ml}$ (Figure 4).

Previous studies conducted have reported cent percent susceptibility to vancomycin.

Table 2: Percentage of vancomycin sensitive Staphylococcus aureus isolates.

\begin{tabular}{|llll|}
\hline Author & Place & Year & $\%$ VSSA \\
\hline Vidhani et al. $^{4}$ & New Delhi & 2001 & $100 \%$ \\
\hline Siddique et al. $^{10}$ & Islamabad & 2002 & $100 \%$ \\
\hline Kakru et al. $^{11}$ & India & 2003 & $100 \%$ \\
\hline Hanumanthappa et al. $^{12}$ & Davangere & 2003 & $100 \%$ \\
\hline Present study & Nellore & 2014 & $82 \%$ \\
\hline
\end{tabular}

VISA have also been reported by many other researchers. In our study VISA is olates were $17 \%$.

Table 3: Percentage of vancomycin intermediate sensitive Staphylococcus aureus isolates.

\begin{tabular}{|c|c|c|c|}
\hline Author & Place & Year & $\%$ VISA \\
\hline Marechese et al. ${ }^{13}$ & Italy & 2000 & $1.1 \%$ \\
\hline Assadullah et al. ${ }^{14}$ & Kashmir & 2003 & $18 \%$ \\
\hline Hakin ST et al. ${ }^{15}$ & Karachi & 2007 & $24 \%$ \\
\hline Present study & Nellore & 2014 & $17 \%$ \\
\hline
\end{tabular}

In our study VRSA isolates were $1 \%$. In our study VRSA found in $1 \%$ when compared to little higher in other studies.
Table 4: Percentage of vancomycin resistant Staphylococcus aureus is olates.

\begin{tabular}{|c|c|c|c|}
\hline Author & Place & Year & $\%$ VRSA \\
\hline S. Assadullah ${ }^{14}$ & Kashmir & 2003 & $3.3 \%$ \\
\hline Present study & Nellore & 2014 & $1 \%$ \\
\hline
\end{tabular}

\section{CONCLUSION}

The observation of present study and various studies infer that staphylococcal infections especially MRSA are common among hospitalized patients and continued to be as a growing problem for the medical personnel. Depending on the results obtained, disc diffusion method should not be conducted to detect the vancomycin susceptibility. MIC testing does not provide clear differentiation between vancomycin-sensitive isolates (VSSA), hVISA, and VISA. Wide spread usage of vancomycin to treat infections caused by MRSA has been reported to result in the emergence of low level resistance. Major antibiotic which was used during our study period in our hospital was vancomycin. Vancomycin is drug of choice for treatment of Methicillin Resistant Staphylococcus aureus (MRSA) infections. MRSA isolates had vancomycin MIC $\geq 4 \mu \mathrm{g} / \mathrm{ml}$ which showed vancomycin susceptibility by disc diffusion may results in treatment failure. ${ }^{16}$

This could be the probable reason for detecting vancomycin resistance among the MRSA isolates in the present study.

Funding: No funding sources Conflict of interest: None declared

Ethical approval: The study was approved by the institutional ethics committee

\section{REFERENCES}

1. Denis O, Nonhoff C, Byl B, Knoop C, BobinDubreux S, Struelens MJ. Emergence of vancomycin intermediate staphylococcus aureus in a Belgian hospital: Microbiological and clinical features. J Antimicrob Chemother. 2002;50:383-91.

2. National Nosocomial Infections Surveillance (NNIS). System report, data summary from January 1990 - May 1999. Am J Infect Control. 1999 June;277:520-32.

3. Waldvogel FA. Staphylococcus aureus. In: Mandell GL, Bennett JE, Dolin R, eds. Principles and Practice of Infectious Diseases. 5th ed. Philadelphia: Churchill Living Stone; 2000: 2069-2092.

4. Vidhani S, Mehndiratta PL, Mathur MD. Study of Methicillin resistant Staphylococcus aureus isolates from high risk patients. Indian J Med Microbiol. 2001; 19:87-90

5. Smith TL, Pearson ML, Wilcox KR, Cruz C, Lancaster MV, Robinson-Dunn B, et al. Emergence of vancomycin resistance in Staphylococcus aureus. N Engl J Med. 1999;340:493-501. 
6. Chaudary, Anupama. Prevalence of methicillin resistance in Staphylococcus aureus. Indian J Med Microbiol. 1999;17(3):154-5.

7. Thompson RL, Cabezudo I, Wenzel RP. Epidemiology of nosocomial infections caused by methicillin resistant Staphylococcus aureus. Ann Intern Med. 1982;97:309-17.

8. Rosenberg J. MRSA in community: WHO's watching. Lancet. 1995;346:132-3.

9. Appelbaum PC. Reduced glycopeptides susceptibility in Methicillin resistant Staphylococcus aureus. Int J Antimicrob Agents . 2007;30(5):398-408.

10. Siddiqi F, Masood MB, Saba N, Samad A, Qayyum M, Qazilbash AA. Antibiogram sensitivity pattern of methicillin resistant Staphylococcus aureus isolates from pus samples. Pak $\mathrm{J}$ Biol Sci. 2002;5(4):491-3.

11. Kakru DK, Assadullah S, Thiker MA, Wani T. Methicillin resistant staphylococcus aureus: need for constant surveillance, stringent control and vigorous treatment measures. Indian $\mathrm{J}$ Pathol Microbiol. 2003;46(1):121-3.

12. Hanumanthappa AR, Chandrappa MR, Rajshekarappa MG. Prevalence of methicillin resistant Staphylococcus aureus in osteomyelitis. Indian J Pathol Microbiol. 2003;46(1):129-30.

13. Marchese A, Balisteri G, Tonoli, Debbia A, Schito G. Heterogenous vancomycin resistance in methicillin resistance $\mathrm{S}$. aureus strains isolate in a large Italian hospital. J Clin Microbiol. 2000;38(2):866-9.

14. Assadullah S, Kakru DK, Thoker MA, Bhat FA, Hussain N, Shah A. Emergence of low level vancomycin resistance in MRSA. Indian $\mathrm{J}$ Med Microbiol. 2003;21(3):196-8.

15. Hakim ST, Arshad S, Iqbal M, Javid SG. Vancomycin sensitivity of staphylococcus aureus isolates from hospital in Karachi, Pakistan. Libyan J Med. 2007;2(4):176-9.

16. Chaudhari CN, Tandel K, Grover N, Bhatt P, Sahni $\mathrm{AK}$, Sen S, et al. In vitro vancomycin susceptibility amongst methicillin resistant Staphylococcus aureus. Med J Armed Forces India. 2014 Jul;70(3):215-9.

DOI: 10.18203/2320-6012.ijrms 20150151

Cite this article as: Sreenivasulu Reddy P, John MS, Vasundhara Devi P, Siva Prasad Reddy B. Detection of vancomycin susceptibility among clinical isolates of MRSA by using minimum inhibitory concentration method. Int J Res Med Sci 2015;3:1378-82. 